Malays. j. med. biol. res.

\title{
Ethylene, 1-MCP and the Antitranspirant Effect of Active Compound-Film Forming Blend
}

\author{
Amha Besufkad Degif ${ }^{1 *}$, Ernst Woltering ${ }^{2}$ \\ ${ }^{1}$ Debre Berhan Agricultural Research Center, Crop Research Directorate, Department of Horticulture, 112 Debre Berhan, ETHIOPIA \\ ${ }^{2}$ Wageningen University and Research Center, Department of Plant Sciences, Horticulture Production Chains (HPC), 6708 WG Wageningen, \\ THE NETHERLANDS
}

Email for Correspondence: amhabesufkad2@gmail.com

\begin{abstract}
Pot plant production in greenhouse is most of the time under high relative humidity and frequent irrigation, whereas during shipment and retailing plants may be exposed to high temperature and infrequent irrigation. These unfavorable conditions often cause water loss, desiccation of plants and short shelf life. To reduce the deteriorating effect of water loss, application of antitranspirants is one of the integral measures to take. In the first experiment, we evaluated the antitranspirant effect of two physiologically active gaseous compounds Ethylene and 1-MCP (1-methylcyclopropane) and their interaction with the successful active compound ABA (Abscisic acid). In the second experiment, with the aim of discovering a more potent antitranspirant, we evaluated the efficacy of an active compoundfilm forming blend. Excised leaves of Spathiphyllum sweet checo were sprayed with different preparations. Weight loss (transpiration) as gram of water per gram of initial leaf weight and stomatal conductance were measured. In the first experiment, $10 \mathrm{ppm}$ Ethylene and $500 \mathrm{ppb} 1-\mathrm{MCP}$ found to reduce water loss conspicuously and negatively interacted with $1.5 \mathrm{mM}$ ABA. In the second experiment, a potent mixture of active compound-film forming antitranspirants: ABA $1.5 \mathrm{mM}+$ Leaf Shine 1:20 followed by SA (Salicylic acid) $5 \mathrm{mM}+$ Leaf Shine 1:20 and SNP (Sodium nitroprusside) 200 $\mu \mathrm{M}+$ Leaf Shine 1:20 were discovered. In both experiments, significant positive correlations were found between weight loss and stomatal conductance $(R=0.975,0.987, P<0.05)$.
\end{abstract}

Key words: Leaf Shine, Abscisic Acid, Salicylic Acid, Sodium nitroprusside, Stomatal conductance

This article is is licensed under a Creative Commons Attribution-NonCommercial 4.0 International License.

Attribution-NonCommercial (CC BY-NC) license lets others remix, tweak, and build upon work non-commercially, and although the new works must also acknowledge \& be non-commercial.

\section{INTRODUCTION}

Pot plant production in the greenhouse is most of the time under high relative humidity and frequent irrigation, whereas during shipment and retailing plants may be exposed to high temperature and infrequent watering. These unfavorable post production environments can cause rapid substrate drying, desiccation of plants and acceleration of senescence, and thus short shelf life (Waterland et.al,. 2010). Water loss is the main post production problem that deteriorate the quality of potted plants and make them unsalable (Van Iersel et al., 2009). For instance, in common potted foliage plants Monsteradeliciosa and Philodendron sp the amount of water loss during shipping and retailing was much higher than their growing environment leading to premature leaf wilting and death (Nerman and Emad 2011). The chief cause of water loss from plants is because of transpiration thru the stomatal opening. The opening of stomata allows gas exchange between the plant and its environment. In the course of stomatal opening, $\mathrm{CO}_{2}$ can enter into the plant and water can be lost as a vapor. Hence, to avoid desiccation and eventual senescence, it is vital to have a right balance between carbon gain and water loss through stomatal movements (Atwell et al. 1999). 
To reduce water loss and its subsequent negative effect on the qualities of pot plants, it is important to develop techniques that can be engaged to reduce transpiration and preserving postharvest quality for extended period (Eukaszewska and Skutnik, 2003). The most essential methods that can be used to reduce transpiration could be the use of antitranspirant agents. Antitranspirant agents are compounds or provisions capable of reducing water loss from leaves of plants. These agents can be clustered into three categories (Prakash and Ramachandran, 2000), I) Filmforming types: that can create a physical barrier between the leaf and the surrounding (e.g. glycerol). II) Reflecting materials: that can reflect the radiation falling on the surface of the leaves to reduce leaf temperature and the light required for signaling during stomatal opening (e.g. Kaolin), and III) Physiologically active stomata closing types: such as ABA and NO, Ethylene etc. capable of affecting metabolic processes in leaf tissues. Naturally, plants react to water deficit by closing stomata mainly mediated by endogenous Abscisic acid (ABA). Exogenous application of $\mathrm{ABA}$ and other active compounds also proved to induce stomatal closure. In our previous experiments and other related studies, ABA is the most potent exogenously applied active compound. However, its efficiency was found to be compromised by the presence of other naturally occurring stomatal closure inducing active compounds like Ethylene (Tanaka. et al., 2005; Desikan et al., 2006). The role of Ethylene in stomatal closure is not clear, in some species it mediates auxin-induced stomatal opening (Merritt et al., 2001). Conversely, in other species it encourages stomatal closure (Acharya and Asman 2009). Tanaka et al., (2005) conveyed the inhibitive effect of Ethylene on ABAinduced stomatal closure in Arabidopsis. Nevertheless, Tanaka et al. (2005) did not show the sole effect of Ethylene in their system. Therefore, to see the effect Ethylene alone, a study conducted by Desikan et al (2006) on Arabidopsis intact leaves evidently showed Ethylene-induced stomatal closure. Furthermore, pre-treatment of leaves with either of Ethylene negative regulators 1-MCP or silver blocked the effect of Ethylene on stomatal closure, indicating Ethylene's effect occurring through its receptors (Desikan et al., 2006). If indeed Ethylene somewhat blocks ABA's effect, theoretically the antitranspirant effect of Ethylene negative regulator 1-MCP may depend on the presence of Ethylene and its interaction with ABA. Moreover, a research on the result of 1-MCP in well-watered and waterstressed cotton plants discovered lower stomatal conductance in 1-MCP treated water stressed cotton plants than untreated controls. Accordingly, the authors concluded that 1-MCP could be used to reduce water loss as a shortterm solution (Eduardo et al., 2010). Hence, all things considered, the first aim of this study was to evaluate the antitranspirant effect of Ethylene and 1-MCP and their interaction with ABA.

Film forming antitranspirants are capable of making a thin glossy layer on the leaf surface so as to physically obstruct stomatal opening. Thus far, Leaf Shine is the most commonly used commercially available film forming antitranspirant in Europe. In addition to its antitranspirant effect, it adds an instant natural gloss to leaves of plants and cut foliages in floral bouquets. It removes water spots and calcium deposits and gives a shiny protective layer that keeps dust away (Chrysal Netherlands., 2013). In our previous experiments, there hasn't been any active compound treatment that surpassed the efficacy of Leaf Shine. Although, our experiment is the first of its kind, with the aim of finding a more potent anti-transpirant, the second aim of this study was to evaluate the efficiency of different concentrations of Leaf Shine blended with successful stomata closing active compounds.

\section{Materials AND Methods}

Both experiments were done in horticultural production chain laboratory of Wageningen University, the Netherlands. Leaves of Spathiphyllum sweet Checo with an intact $10 \mathrm{~cm}$ petiole and $30 \mathrm{ml}$ of tap water filled in a plastic tube enclosed by a rubber cap were used as a plant material and vase solution respectively. Matrix solution (producer unknown) as carrier solution of ABA in the first experiment, film forming anti-transpirant: Chrysal Leaf Shine concentrate solution diluted 1:20 and 1:40 with deionised water (Chrysal International B.V, Naarden, the Netherlands) and active compounds: ABA 10\% w/v (Valent USA, Walnut Creek, CA, united states of America), Sodium nitroprusside dehydrate (SNP) and Salicylic acid sodium salt (2 hydroxy benzoic acid) (SA), (from SigmaAldrich Corporation, Steinheim Germany ) were used. Spraying was done under the flow hood using a very fine airbrush sprayer powered by pressurized gas. The abaxial and adaxial surfaces of excised leaves were sprayed homogenously up until the spraying solution started to flood off the leaf surface. After spraying was done, leaves were left to dry outside the flow hood in the laboratory for about two hours. For the first experiment, after the respective spray was done and the necessary measurements were taken, sprayed leaves were transferred into three 70 liter enclosed metal containers. Control treatments, leaves to be treated with ethylene and leaves to be treated with 1-MCP were placed in the first, second and third container respectively. Ethylene and 1-MCP were injected into the second and third tank using a medical syringe and needle. With the aim of having an optimised control treatment, leaves to be treated with Ethylene and 1-MCP were also sprayed with matrix. After spending 72 hours in the metal tank, all treatments were taken out and transferred into the flow hood and kept in it for ten days. For the second experiment, deionised water was used as a carrier solution for active compounds. Besides, to compensate for the diluting effect of Leaf Shine, the concentration of active compounds was raised by $5 \%$. To properly mix active compounds with Leaf Shine, magnetic stirrers were used for 20 minutes. To ensure maximum 
transpiration sprayed leaves in the flow hood were exposed to 24 hour light and continuous ventilation. In the course of both experiments, temperature and relative humidity were revolving between 20 to $22{ }^{\circ} \mathrm{C}$ and 45 to 50 respectively.

In the beginning of each experiment, initial leaf weight of each leaf was determined. After leaves were sprayed and dried, the weight of the leaf + tube + vase solution were measured and recorded as a base. Throughout the experimental period, weight loss from the system was measured and recorded every 24 hour. In addition, at the last day of each experiment, leaf area was measured using LI-3100C Area Meter. Before doing the actual area measurement, the area metre was turned on for 15 minutes and calibrated. Daily water loss from the foliage surface was calculated using a simple formula: Daily water loss $=($ Weight of the leaf + tube +vase solution at day 0 , $1,2 \ldots 10$ - weight of leaf + tube +vase solution at day 1,2,3...10). The daily water transpired from the leaf surfacewas then calculated both in terms of amount of water lost per grams of initial leaf weight and per centimetre square leaf area by using the formula: Transpiration $1=(($ Weight of the leaf + tube +vase solution at day $0,1,2 \ldots(n)-$ weight of leaf + tube +vase solution at day 1, 2, 3...(n) / initial leaf weight $))$ and Transpiration $2=(($ Weight of the leaf + tube $+v a s e$ solution at day $0,1,2 \ldots(n)$ - weight of leaf + tube +vase solution at day 1, 2, 3...(n)/leaf area)). Furthermore, total water loss over time was calculated by adding transpiration at a given time points. Stomatal conductance was measured each morning between 10:00 to 12:00 hours by using SC-1 leaf Porometer for stomatal conductance measurements (Decagon Devices Inc., Pullman, USA).

The design of the experiment was CRD with three replications (leaves as a replication), and data analysis was done using SAS version 9.1. Moreover, to see differences in weight loss (transpiration) and stomatal conductance, one way ANOVA, followed by a Tukey mean separation test was carried out. Correlation analysis was also done to show relationships between the measured parameters.

\section{Results ANd Discussion}

\section{First Experiment (Ethylene and 1-MCP)}

The goal of this experiment was to evaluate the antitranspirant effect of Ethylene and its negative regulator 1-MCP and to explore the possible interaction effect of Ethylene and 1-MCP with ABA. For either of the parameters considered, statistically significant differences were not observed between the test treatments. However, significant differences were existent between the test treatments and weaker controls (tap water, matrix) (Table 1). Accordingly, Ethylene and 1-MCP reduced water loss and stomatal conductance substantially than the least effective control treatments. ABA + Ethylene or 1-MCP reduced water loss better than the sole Ethylene or 1-MCP and Ethylene reduced water loss more successfully than its negative regulator 1-MCP. Generally, with the respective concentrations tested, ABA was a more potent antitranspirant than Ethylene and 1-MCP and the performance of ABA was reduced either by Ethylene or 1-MCP. 10 ppm Ethylene and 500 ppb 1-MCP reduced the efficacy of $1.5 \mathrm{mM}$ ABA by 6 and 10\% respectively. Additionally, with the aim of showing the relationship between stomatal conductance and weight loss, a correlation analysis was also carried out and revealed a significant positive correlation $(\mathrm{R}=0.975, \mathrm{P}<0.05)$ (Figure 1).

Table 1: Total weight loss at the $13^{\text {th }}$ day and cumulative stomatal conductance of Spathiphyllum sweet checo expressed as $\mathrm{g} / \mathrm{g}$ of initial leaf weight and $\mathrm{mmol} / \mathrm{m}^{2} / \mathrm{s}$ respectively. Values are based on the three leaves per treatment. Significant differences are denoted by different lower case letters $(a, b)$.

\begin{tabular}{|l|c|c|}
\hline Treatments & Weight loss $(\mathrm{g} / \mathbf{g})$ & Stomatal conductance(mmol/m $\mathbf{2} / \mathbf{s})$ \\
\hline Leaf Shine 1:20 & $1.030(\mathrm{a})$ & $0.000(\mathrm{a})$ \\
\hline Matrix + ABA 1.5 mM & $1.116(\mathrm{ab})$ & $0.800(\mathrm{ab})$ \\
\hline Matrix + ABA 1.5 mM +Ethylene 10 ppm & $1.178(\mathrm{ab})$ & $1.100(\mathrm{ab})$ \\
\hline Matrix + ABA 1.5 mM +1-MCP 500 ppb & $1.228(\mathrm{ab})$ & $1.400(\mathrm{ab})$ \\
\hline Matrix + Ethylene 10 ppm & $1.233(\mathrm{ab})$ & $1.600(\mathrm{~b})$ \\
\hline Matrix + 1-MCP 500 ppb & $1.332(\mathrm{~b})$ & $1.700(\mathrm{~b})$ \\
\hline Matrix & $1.648(\mathrm{c})$ & $9.767(\mathrm{c})$ \\
\hline Tap Water & $1.828(\mathrm{c})$ & $12.267(\mathrm{~d})$ \\
\hline Mean & 1.324 & 3.579 \\
\hline Sig & $*$ & ${ }^{*}$ \\
\hline CV & 7.1 & 14.0 \\
\hline
\end{tabular}




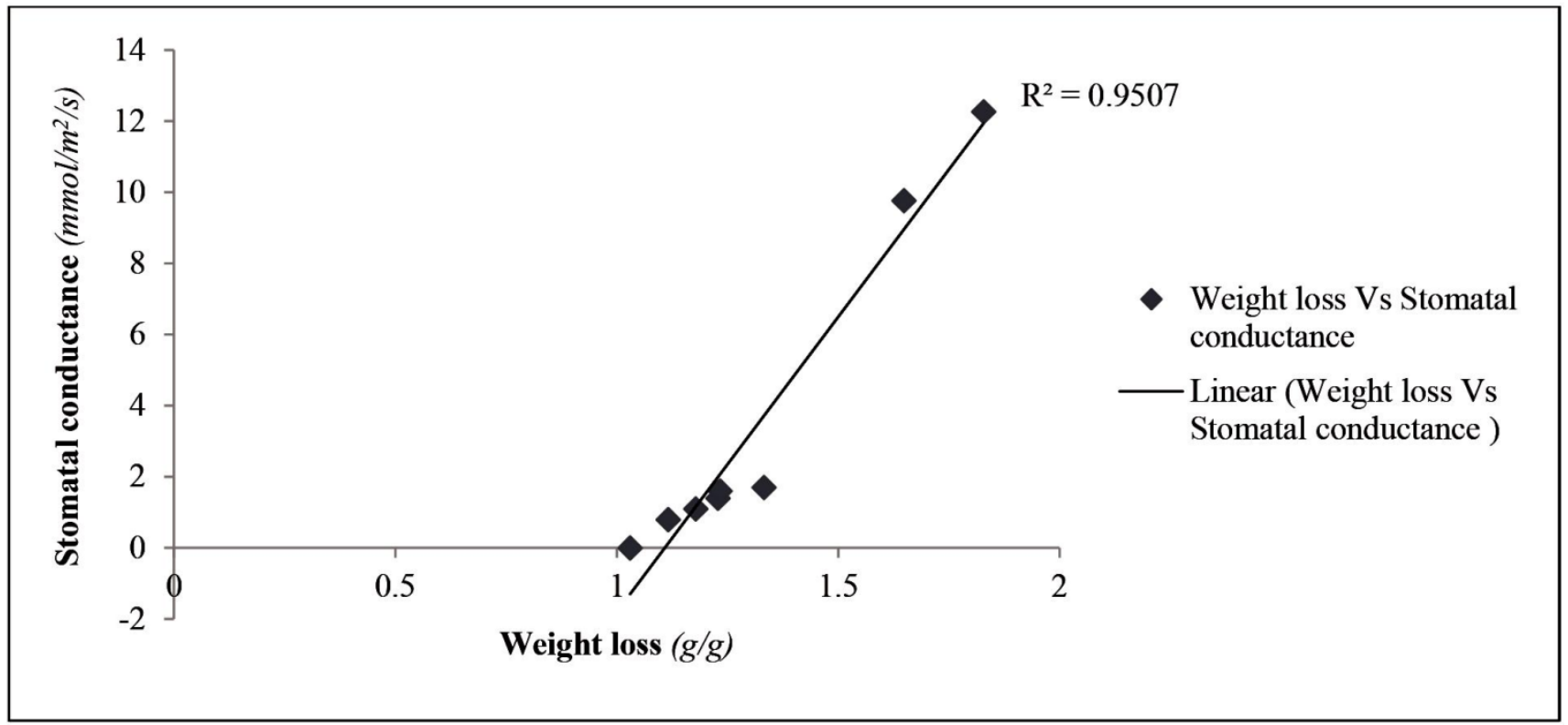

Figure 1: Graph showing the relationship between weight loss $(\mathrm{g} / \mathrm{g})$ and stomatal conductance $\left(\mathrm{mmol} / \mathrm{m}^{2} / \mathrm{s}\right)$ on Spathiphyllum sweet checo. The $\mathrm{X}$ axis shows weight loss and $\mathrm{Y}$ axis represents stomatal conductance of all treatments. Values are averages of the three leaves per treatment.

Parallel to our result, previous observations also confirmed the ability of Ethylene to induce stomatal closure and the subsequent reduction in water loss (Madhavan et al., 1983; Acharya and Asman 2009). A detailed study byDesikan et al., (2006) convincingly showed the ability of Ethylene to induce stomatal closure in intact leaves of Arabidopsis. Ethylene supplied either directly as gas or generated from its immediate precursor ACC (1aminocyclopropane-1-carboxylic acid) initiated stomatal closure 30 minutes after exposure. To further confirm the involvement of Ethylene on stomatal closure they pretreated intact Arabidopsis leaves with Ethylene negative regulator 1-MCP and silver thiosulfate and it inhibited Ethylene-induced stomatal closure. As reported by Desikan et al., (2006), to cause stomatal closure Ethylene might have induced the generation of $\mathrm{H}_{2} \mathrm{O}_{2}$ mediated by the NADPH oxidase isoform AtrbohF. Detailed information on the sole antitranspirant effect of 1-MCP cannot be found, however a study by Eduardo et al., (2010) displayed the ability of 1-MCP to reduce stomatal conductance of water stressed cotton plants.

The outcome of our experiment also clearly demonstrated the capacity of Ethylene and 1-MCP to inhibit the antitranspirant effect of ABA. Likewise, the inhibitory effect of Ethylene has also been reported (Tanaka et al., 2005; Desikan et al., 2006; Chen et al., 2013). Similar to the observation of Desikan et al., (2006) andChen et al., (2013), Ethylene indeed triggered stomatal closure. Nonetheless, in the presence of ABA Ethylene might have functioned the other way around. Remarkably, 1-MCP compromised the efficiency of ABA powerfully than ethylene. 1-MCP is the so called negative regulator of Ethylene and the inhibitory effect of Ethylene on ABA was previously reported. As a result of this, we thought the effect of 1-MCP would be the reverse, but according to our result, both Ethylene and 1-MCP can reduce transpiration solely and can diminish the antitranspirant effect of ABA. Therefore, at least for concentrations we used, it seems reasonable to conclude that when ABA is used as stomatal closing agent, the presence of both Ethylene and 1-MCP better be avoided. On the other hand, if stomatal closure is targeted thru the application of gaseous compounds, both Ethylene and 1-MCP can be used

\section{Second Experiment (Active compound-Film forming blend)}

This experiment was done to assess the possibility of improving the antitranspirant effect of a film forming antitranspirant by incorporating active compounds in it. To evaluate the possibility of getting a combined positive effect, three active compounds with their respective successful concentrations: ABA 1.5mM, SA 5 mM and SNP $200 \mu \mathrm{M}$ were incorporated into two Leaf Shine concentrations: Leaf Shine 1:20 and Leaf Shine 1:40. Note: Combined positive effect implies when $\mathrm{AB}>\mathrm{A}$ and B. For both parameters considered, statistically significant differences were displayed mainly between treatments with a Leaf Shine component and without a Leaf Shine component (Table.2). 
Table 2: Total weight loss at the $10^{\text {th }}$ day and cumulative stomatal conductance of Spathiphyllum sweet checo expressed as $\mathrm{g} / \mathrm{g}$ of initial leaf weight and $\mathrm{mmol} / \mathrm{m}^{2} / \mathrm{s}$ respectively. Values are based on the three leaves per treatment. Significant differences are denoted by different lower case letters $(a, b)$.

\begin{tabular}{|c|c|c|}
\hline Treatments & Weight loss $(\mathrm{g} / \mathrm{g})$ & Stomatal conductance $\left(\mathrm{mmol} / \mathrm{m}^{2} / \mathrm{s}\right)$ \\
\hline $\mathrm{dw}+\mathrm{ABA} 1.5 \mathrm{mM}+\mathrm{LS} 1: 20$ & $0.581(\mathrm{a})$ & $0.000(\mathrm{a})$ \\
\hline $\mathrm{dw}+\mathrm{SA} 5 \mathrm{mM}+\mathrm{LS} 1: 20$ & $0.621(\mathrm{ab})$ & $0.000(\mathrm{a})$ \\
\hline $\mathrm{dw}+\mathrm{SNP} 200 \mu \mathrm{M}+\mathrm{LS1}: 20$ & $0.636(\mathrm{abc})$ & $0.172(\mathrm{a})$ \\
\hline Leaf Shine 1:20 & $0.703(\mathrm{abc})$ & $2.400(b)$ \\
\hline Leaf Shine 1:40 & $0.738(\mathrm{abc})$ & $2.800(b)$ \\
\hline $\mathrm{dw}+\mathrm{ABA} 1.5 \mathrm{mM}+\mathrm{LS} 1: 40$ & $0.797(\mathrm{bc})$ & $1.100(\mathrm{ab})$ \\
\hline $\mathrm{dw}+\mathrm{SA} 5 \mathrm{mM}+\mathrm{LS} 1: 40$ & $0.801(\mathrm{bc})$ & $1.200(\mathrm{ab})$ \\
\hline $\mathrm{dw}+\mathrm{SNP} 200 \mu \mathrm{M}+\mathrm{LS} 1: 40$ & $0.810(\mathrm{c})$ & $0.900(a b)$ \\
\hline $\mathrm{dw}+\mathrm{SA} 5 \mathrm{mM}$ & $1.947(\mathrm{~d})$ & $16.800(\mathrm{c})$ \\
\hline $\mathrm{dw}+\mathrm{SNP} 200 \mu \mathrm{M}$ & $1.952(\mathrm{~d})$ & $16.167(\mathrm{c})$ \\
\hline $\mathrm{dw}+\mathrm{ABA} 1.5 \mathrm{mM}$ & $1.985(\mathrm{~d})$ & $20.900(\mathrm{~d})$ \\
\hline Tap water & $2.103(\mathrm{~d})$ & $21.100(\mathrm{~d})$ \\
\hline Mean & 1.139 & 6.961 \\
\hline Sig & * & * \\
\hline $\mathrm{Cv}$ & 5.6 & 10.2 \\
\hline
\end{tabular}

A combined positive effect was found between LS 1:20 and active compounds, both in terms of the sole efficacy of Leaf Shine 1:20 and active compound treatments. With their respective concentration, ABA improves the effectiveness of Leaf Shine 1:20 better than SA and SNP. In numerical terms, Leaf Shine 1:20 + 1.5 mM ABA, Leaf Shine 1:20 + 5mM SA and Leaf Shine 1:20 + $200 \mu \mathrm{M}$ SNP reduced water loss 19, 12 and $11 \%$ better than sole Leaf Shine 1:20 respectively. Nevertheless, there was no combined positive effect between Leaf Shine 1:40 and active compounds. About the sole efficiency of Leaf Shine 1:40, there was rather a combined negative effect. SNP reduced its efficiency higher than ABA and SA (Table 2). Similar to the first experiment, the relationship between weight loss and stomatal conductance were very strong with a significant positive correlation $(\mathrm{R}=0.987, \mathrm{P}<0.05)($ Figure 2$)$.

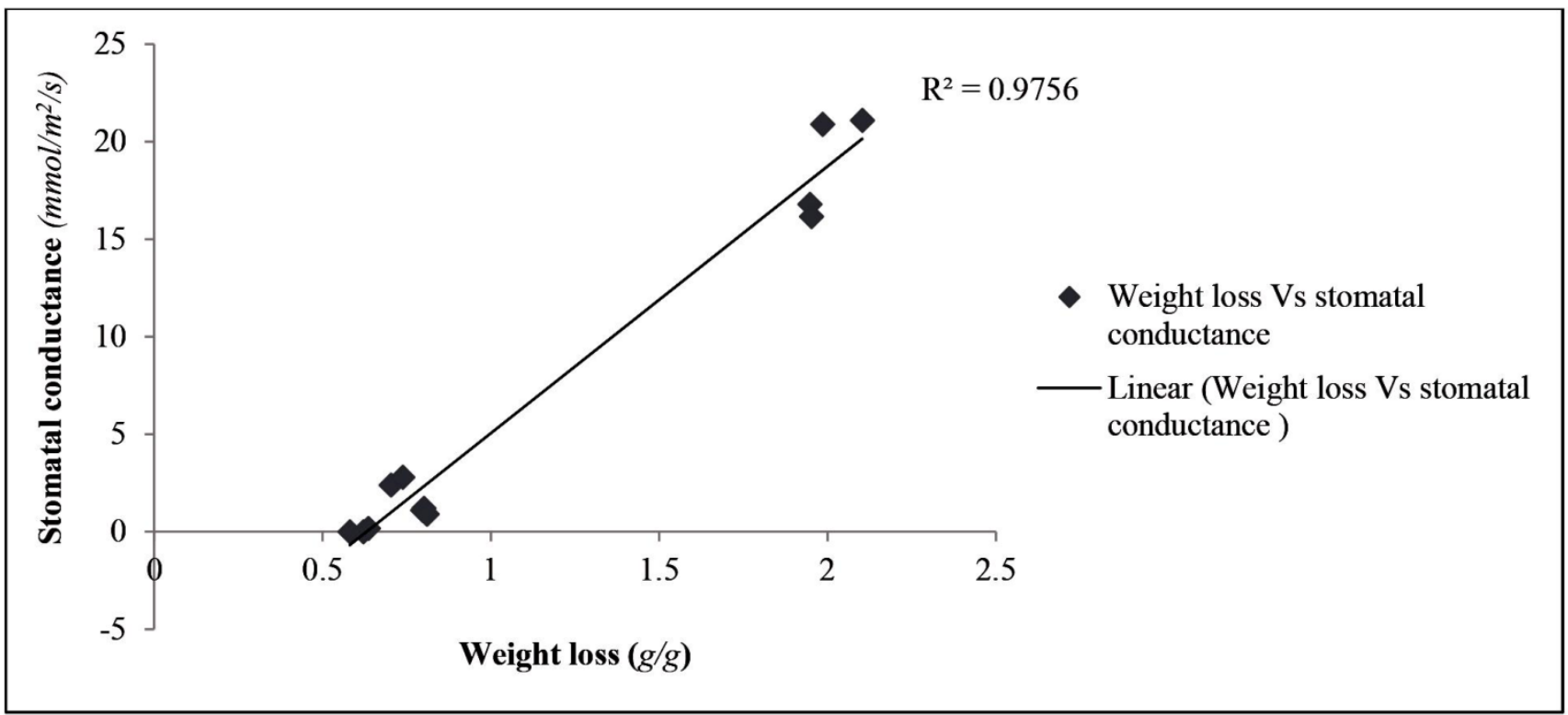

Figure 2: Graph showing the relationship of weight loss $(\mathrm{g} / \mathrm{g})$ and stomatal conductance $\left(\mathrm{mmol}_{\mathrm{m}} / \mathrm{s}\right)$ on Spathiphyllum sweet checo. The $\mathrm{X}$ axis shows weight loss and $\mathrm{Y}$ axis represents stomatal conductance of all treatments. Values are averages of the three leaves per treatment.

The chemical interaction between active compounds and film forming antitranspirants was difficult to know. Nevertheless, the combined positive effect might have been because Leaf Shine 1:20 is more glue-like than Leaf shine 1:40 so as to retain active compounds on the leaf surface for extended period. In our other dissimilar experiments, on 
the same plant material, when matrix (a glue-like carrier solution with no antitranspirant effect) was used as carrier solution for active compounds, $1.5 \mathrm{mM}$ ABA followed by 5mM SA and $200 \mu \mathrm{M}$ SNP were the top three successful active compound treatments. However, when these active compounds were blended with the less diluted Leaf Shine, $1.5 \mathrm{mM}$ ABA followed by 5mM SA and $200 \mu \mathrm{M}$ SNP produced a better combined positive effect. Therefore, for the reason that both Leaf Shine and matrix are glue like, it looks, as if the role of the less diluted Leaf Shine was retaining these active compounds on the leaf surface while performing its own antitranspirant effect. Active compounds with their respective concentration compromised the antitranspirant effect of the more diluted Leaf Shine, and since we haven't done further analysis and no related reports were found, what might happened is not yet clear and should be the focus of future research.

Generally, for the concentrations of Leaf Shine and active compounds used, their combination may or may not produce a successful blend. Regarding Leaf Shine 1:20 and active compounds with their respective concentration, there was a combined positive effect and this specific combination can be used as a powerful anti-transpirant. The appearance of leaves sprayed with active compounds was not appealing as Leaf Shine sprayed leaves. Nonetheless, the ability of active compounds to improve the efficacy of a film forming antitranspirant Leaf Shine may open another venue for their future significance.

\section{ACKNOWLEDGEMENTS}

I want to forward my sincere appreciation to Netherlands Fellowship program (NFP) for funding my study and to my thesis supervisor Professor Dr. Ernst Woltering for his incessant guidance and provision throughout the study period. I also want to acknowledge Mr. Sasan Ali for giving me the necessary information about the Porometre and stomatal conductance measurements. I also want to thank the head of horticultural production chain laboratory Mr. Arjen Van Peppel for his day to day assistance.

\section{REFERENCES}

Acharya B and Assmann S (2009). Hormone interactions in stomatal function. Plant Molecular Biology, 69: 451-462.

Atwell B, Kriedemann P, Turnbull C (1999). Plants in Action: adaptation in nature, performance in cultivation. MacMillan Publishers Australia PTY LTD.

Chen L, Dodd I, Davies W, and Wilkinson S (2013). Ethylene limits abscisic acid or soil drying-induced stomatal closure in aged wheat leaves. Plant, Cell \& Environment, 10.1111-1123.

Chrysal Netherlands., 2013. Chrysal leaf Shine. Available at: / http:/ /www.chrysal.nl.

Desikan R, Last K, Harrett-Williams R, Tagliavia C, Harter K, Hooley R, Hancock J, and Neill S (2006). Ethylene-induced stomatal closure in Arabidopsis occurs via AtrbohF-mediated hydrogen peroxide synthesis. The Plant Journal, 47: 907-916.

Eduardo M, Kawakami, Derrick M, Oosterhuis, John L and Snider (2010). Physiological Effects of 1-Methylcyclopropene on WellWatered and Water-Stressed Cotton Plants.J Plant Growth Regul, 29:280-288.

Łukaszewska A, Skutnik E (2003). Guide to florists. Copyright by, p. 156.

Madhavan S, Chrominiski A and Smith B (1983).Effect of ethylene on stomatal opening in tomato and carnation leaves. Plant Cell Physiol, 24: 569-572.

Nermeen T and Emad A (2011). Influence of some chemical compounds as antitranspirant agents on vase life of Monsteradeliciosa leaves. African Journal of Agricultural Research, 6:132-139.

Prakash M and Ramachandran K (2000).Effects of moisture stress and antitranspirants on leaf chlorophyll. J Agron Crop Sci, 184: 153-156.

Tanaka Y, Sano T, Tamaoki M, Nakajima N, Kondo N and Hasezawa S (2005). Ethylene inhibits abscisic acid-induced stomatal closure in Arabidopsis. Plant Physiol, 138, 2337-2343.

Van Iersel, Seader M and Dove S (2009). Exogenous abscisic acid application effects on stomatal closure, water use, and shelf life of hydrangea (Hydrangea macrophylla).J. Environ. Hort, 27:234-238.

Waterland N, Finer J and Jones M (2010). Abscisic Acid Applications Decrease Stomatal Conductance and Delay Wilting in Drought-stressed Chrysanthemums.Hort Technology, 20:896-901. 